\title{
Improved Bactericidal Activity of Polyethylenimine Grafted Graphene Oxide Nanocomposite against Staphylococcus aureus and Escherichia coli
}

\author{
Wasim Akhtar ${ }^{1,2}$, Muhammad Shoaib ${ }^{1,2}$, Imran Mahmood Khan ${ }^{1,2}$, Sobia Niazi ${ }^{1,2}$, Husnain Raza ${ }^{3}$, \\ Umar Shahbaz ${ }^{4}$, Lin Yue ${ }^{* 1,2}$ and Zhouping Wang*1,2
}

${ }^{1}$ State Key Laboratory of Food Science and Technology, Jiangnan University, P.R. China

${ }^{2}$ School of Food Science and Technology, Jiangnan University, P.R. China

${ }^{3}$ School of Food Science and Biological Engineering, Jiangsu University, Zhenjiang, P.R. China

${ }^{4}$ State Key Laboratory of Carbohydrate Chemistry and Biotechnology, School of Biotechnology, Jiangnan University, Ministry of Education, P.R. China

*Corresponding author: Lin Yue and Zhouping Wang, State Key Laboratory of Food Science and Technology, Jiangnan University, PR China

\section{ARTICLE INFO}

Received: April 16, 2020

Published: 幽 April 27, 2020

Citation: Wasim Akhtar, Muhammad Shoaib, Lin Yue, Zhouping Wang, et al. Improved Bactericidal Activity of Polyethylenimine Grafted Graphene Oxide Nanocomposite against Staphylococcus aureus and Escherichia coli. Biomed J Sci \& Tech Res 27(2)2020. BJSTR. MS.ID.004477.

Abbreviations: 2-D: 2-Dimensional; GO: Graphene Oxide; PEG: Polyethylene Glycol; ROS: Reactive Oxygen Species; PEI: Polyethylenimine; QPEI: Quaternate Polyethylenimine; NHS: N-hydroxy-Sulfosuccinimide Sodium Salt; UPW: Ultrapure Water; EDC: Ethyl Dimethylamino Carbodiimide; TEM: Transmission Electron Microscopy; FTIR: Fourier-Transform Infrared Spectrophotometer; LB: Luria Bertani

\section{ABSTRACT}

Global emergence of pathogenic bacteria is becoming a major concern to human's health because of the resistance of bacteria towards antibiotics overuse. Nanotechnology has gained intense attention to overcome these challenges with the development of antibacterial nanomaterial with distinctive physicochemical properties. In this work, we have prepared antibacterial Polyethylenimine grafted graphene oxide (PEI-GO) by functionalization of GO with PEI through the formation of $\mathrm{C}-\mathrm{N}$ bond with amine groups of PEI and carboxyl and epoxy groups from GO. The characterization of PEIGO was done by FTIR, XRD, TEM, Raman spectroscopy, and UV. spectrophotometry for the confirmation of the as-prepared nanocomposite. PEI-GO showed high antibacterial activity as compared to GO and PEI against Gram-positive Staphylococcus aureus ( $S$. aureus) and Gram-negative Escherichia coli (E. coli), killing almost $100 \%$ S. aureus and $90.5 \%$ E. coli bacteria with $20 \mu \mathrm{g} / \mathrm{mL}$ of PEI-GO. Moreover, time dynamic bactericidal activity reveals that antibacterial toxicity of PEI-GO is inversely proportional to the concentration and contact time of bacteria.

The high antibacterial action of PEI-GO was assigned to the synergistic effect of both material, the positive charge of PEI-GO interact with the negatively charged membrane of bacteria disturbing the membrane while sharp edges of GO penetrate the membrane resulting in the disruption of bacterial cell structure and ultimately cell death. The higher susceptibility of $S$. aureus was associated with lacking outer membrane, whereas E. coli with an outer membrane indicated slight resistance compared to $S$. aureus. Our result shows that PEI-GO could be an attractive antibacterial agent for its use to combat the development of bacterial resistance.

Keywords: Graphene Oxide; Antibacterial; Nanocomposite; Polyethylenimine

\section{Introduction}

Recently the worldwide emergence of bacterial resistance towards antibiotics and drugs is a serious threat to public health, resulting in the prevalence of infectious disease and increase morbidity rate around the world. Furthermore, various effective antibiotics, that were developed to fight bacterial infections are no longer potent due to the emergence of bacterial resistance [1-3]. To control the evolution and environmental adaptation of numerous microbial strains is one of the prime challenges for the research community [4]. Therefore, the development of new approaches needs to be immediately explored to combat drug-resistant bacteria. In the past decade, the massive advancement in nanotechnology has attracted intensive attention [5], leading to the development of non-antibiotic, biocompatible, antimicrobial nanomaterial with 
distinctive physical and chemical properties [6]. Graphene, since after its discovery has acquired colossal attention of scientists, because of its scale-up production, its synergistic effect with other material, significant physicochemical $[7,8]$, electronic properties [9], and large surface area [10], allowing its application in the field of drug delivery [11], tissue engineering [12], sensors and biosensors development [13,14], cell imaging [15], photothermal therapy [16] as well as in bacterial growth inhibition [17].

Graphene is the $1^{\text {st }} 2$-dimensional (2D), single atomic sheet of graphite, hexagonally arranged lattice structure of $\mathrm{sp}^{2}$ hybridized carbon atoms $[7,18,19]$. Likewise, Graphene oxide (GO) is the derivatives of graphene with $\mathrm{sp}^{3}$ hybridization of carbon atoms, highly oxidative, obtained by chemical oxidation and subsequently exfoliation [20], hydrophilic in nature, possessing a large number of oxygen-bearing functional groups including epoxy and hydroxyl on the basal plane, and carboxyl groups on the edges $[21,22]$. These oxygen-containing functional groups assist the chemical functionalization of GO sheet with other molecules [22]. Innumerable studies of GO functionalization with polyethylene glycol (PEG), Polyethylenimine, chitosan, cystamine, for their application in drug delivery, tissue engineering, bioimaging, gene delivery and bactericidal activity [12,23-26] has been reported. Various studies on the antibacterial effect of GO has reported its bactericidal property through somatic damage and oxidative stress $[17,27,28]$. Along with physical damage [27], oxidative mechanism also plays its part in deactivating bacterial cell by reactive oxygen species (ROS) production in GO [26,29].

Liu et al. have studied the antibacterial effect of four different graphene-based material (GO, Gt, Gr, rGO) and found GO with higher bactericidal property comparing to others [30]. In another study done by Barbolina et al. observed no antibacterial effect of pure GO against Gram-positive S. aureus and Gram-negative E. coli
[31]. Furthermore, other studies on the functionalization of GO with various nanoparticles and polymers has been reported to improve its antibacterial property and stabilization [32,33]. Polyethylenimine (PEI) is polycationic synthetic polymer prepared from aziridine by polymerization, hydrophilic, branched or unbranched, containing primary, secondary and tertiary amino group $\left(-\mathrm{NH}_{2}\right)$ in its structure, that can be protonated $[34,35]$. Because of being highly positive charge, high membrane permeability and exceptional transferability, PEI is extensively used in gene transfer and drug delivery $[34,36]$. PEI itself is considered as microbicidal agent, and it is also used as an enhancer in the field of microbiology to strength the antibacterial property of both hydrophilic and hydrophobic antibiotic [37].

Gao et al. prepared quaternate Polyethylenimine (QPEI), that exhibited excellent antibacterial activity, associated with the degree of cationic charge on its backbone chain [38]. A study by Azevedo et al. used nanoPEI to inhibit bacterial growth and concluded that the antibacterial property of PEI mainly depends on high concentration as well as species specificity [39]. PEI can be linked to GO via nucleophilic addition reaction between the PEI amine group and carboxyl and epoxy group of graphene oxide [40,41]. Here in, keeping in view the antibacterial property of both the materials, we have prepared PEI grafted graphene oxide (PEI-GO) nanocomposite through the functionalization of PEI on the graphene sheet via $\mathrm{C}-\mathrm{N}$ bond. The schematic illustration is presented in Figure 1. The nanocomposite was observed through various characterization techniques. The antibacterial activity of as produced PEI-GO was conducted against two bacterial strains (S. aureus and E. coli as the representative bacteria), besides that time dynamic bactericidal activity was also studied. It is expected that our nanocomposite will have excellent biocidal activity because of the synergy effect of PEI and GO.

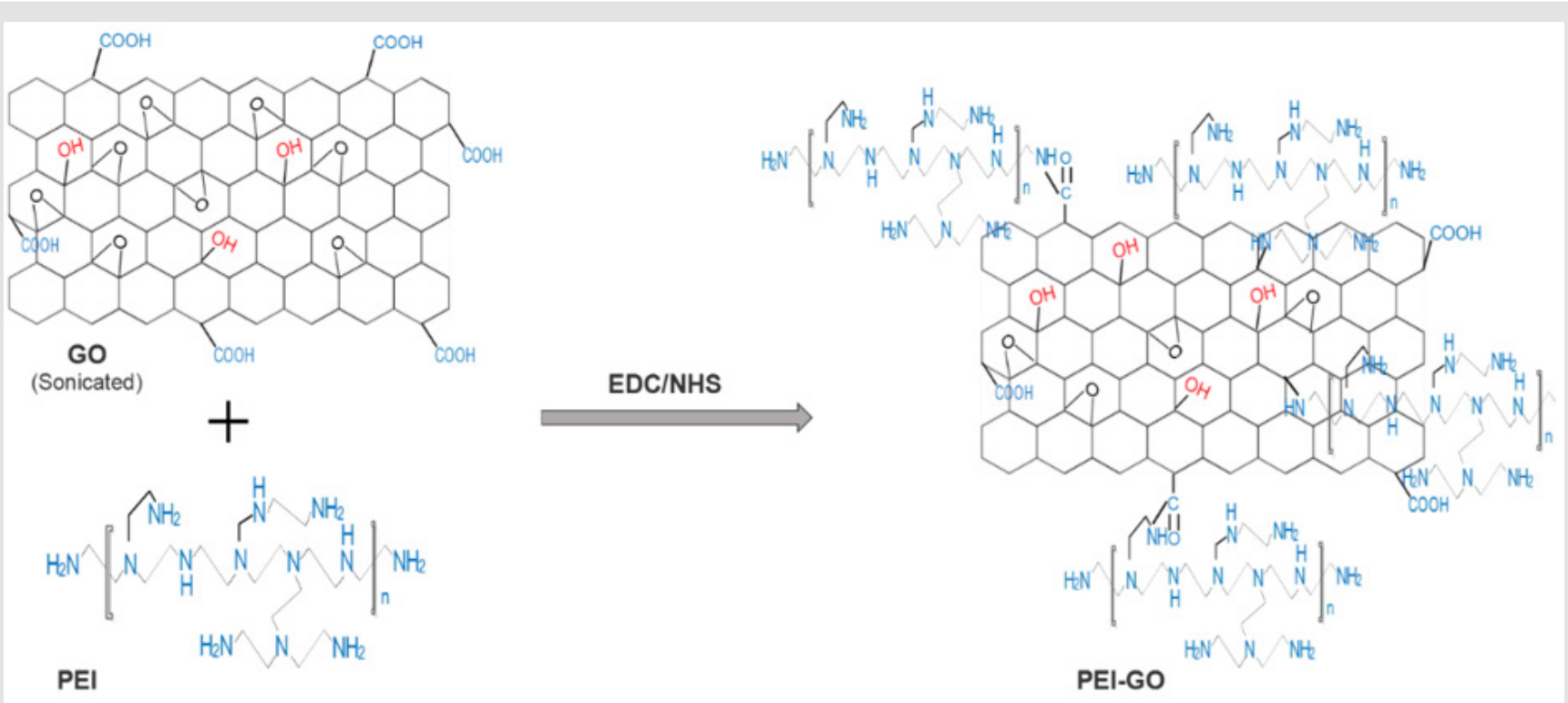

Figure 1: Schematic illustration of PEI-GO nanocomposite. 


\section{Materials and Methods}

\section{Reagents}

Graphene Oxide (GO) was obtained from Nanjing XFNANO Materials Tech Co., Ltd. (Nanjing, China). Polyethylenimine (PEI) was acquired from Aladdin Chemistry Co., Ltd. (China). Ethyl-3(3'-dimethylamino-propyl) carbodiimide (EDC) and N-hydroxysulfosuccinimide sodium salt (NHS) were bought from Sigma Aldrich co., (Shanghai, China). Ultrapure water (UPW) was used for preparing all the aqueous solution.

\section{Preparation of PEI-GO Nanocomposite}

Graphene oxide was grafted with PEI according to the previously reported process with little adjustment [42]. $20 \mathrm{mg}$ of graphene oxide was ultrasonicated in $10 \mathrm{~mL}$ of ultrapure water for 2 hours to get a homogeneous dispersion. Then $100 \mathrm{mg}$ PEI was added and sonicated for an additional 30 minutes. After that, 60 mg EDC and $30 \mathrm{mg}$ NHS were added gradually in the dispersion and sonicated for a further 15 minutes. Next, the material in the flask was shifted on the magnetic stirrer for one day, and speed of the stirrer was adjusted to $850 \mathrm{rpm}$. The whole procedure was performed at ambient temperature. The composite was obtained by centrifugation followed by three washing with ultrapure water and subsequently dried in the oven at $50{ }^{\circ} \mathrm{C}$.

\section{Characterization}

Transmission electron microscopy (TEM) was performed at an accelerating voltage of $200 \mathrm{kV}$ on a JEOL model $2100 \mathrm{HR}$ instrument (TEM, JEOL, Ltd., Japan). Shimadzu UV-1800 spectrophotometer was used to carry out the UV-vis absorption spectra in the range of 200 to 800 for nanocomposite (Shimadzu, Japan). Fouriertransform infrared spectrophotometer (FTIR) was used to obtain FTIR spectra on Nicolet Nexus 470 FTIR Spectrophotometer (Thermo Electron co., USA) at a wavelength of 500 to $4000 \mathrm{~cm}^{-1}$. The $\mathrm{X}$-ray diffraction patterns were taken on a Bruker D8 advance X-ray diffractometer with $\mathrm{Cu}-\mathrm{K} \alpha \mathrm{X}$-ray radiation $(\lambda=1.5406 \AA)$ with $40 \mathrm{kV}$ voltage at the $2^{\circ}$ /minute scanning rate (Bruker AXS Ltd., Germany). Raman spectra were measured using LABRAM HR 800 microscopy confocal Raman spectrometer using $532 \mathrm{~nm}$ excitation wavelength with x50 objective (HORIBA Corporation, Japan). Nanocomposite zeta potential was measured using zeta potential instrument by diluting the sample in water (Malvern zeta-sizer nano ZS).

\section{Bacterial Culture}

First two bacterial strains Gram-positive Staphylococcus aureus (S. aureus) ATCC 29213 and Gram-negative Escherichia coli (E. coli) ATCC 25922 were grown overnight on Luria Bertani (LB) agar plates at temperature $37^{\circ} \mathrm{C}$ in an incubator. Then a single colony of bacterial strains from above plates were cultured overnight in liquid LB media at $37{ }^{\circ} \mathrm{C}$ in an incubator shaker. Afterwards, the bacteria were harvested by centrifugation (8000) at the mid-exponential growth phase and washed using sterilized saline solution $(0.85 \%$ $\mathrm{NaCl}$ ) to remove extra residual macromolecules [17]. Optical density
$\left(\mathrm{OD}_{600 \mathrm{~nm}}\right)$ was measured by spectrophotometer after resuspending the pellets in saline solution and diluted to $10^{6} \mathrm{CFU} / \mathrm{mL}$.

\section{Antibacterial Test}

For antibacterial assay, $10 \mu \mathrm{L}$ of bacterial suspensions were mixed in $900 \mu \mathrm{L}$ of saline solution comprising a different concentration of GO, PEI, PEI-GO. Tubes containing the above suspensions were transferred into incubator shaker for 5 hours at $37^{\circ} \mathrm{C}$ with shaking speed $200 \mathrm{rpm}$. Afterwards, $100 \mu \mathrm{L}$ of suspension from the above samples were spread evenly on the LB agar plates, and all the plates were incubated overnight at $37^{\circ} \mathrm{C}$ [43]. The same procedure was adopted for the control sample without any material treatment. Bacterial colonies were counted on LB agar plates and survival percentage was calculated by compairing control group. All experiments were repeated three times.

\section{Minimum Inhibitory Concentration (MIC)}

Minimum inhibitory concentration of GO, PEI, PEI-GO were ascertained by the previously reported microdilution technique [44] with little modification. In brief, log phase S. aureus and E. coli $\left(10^{6} \mathrm{CFU} / \mathrm{mL}\right)$ were incubated in 96-well microtiter plates with different concentrations $(2,4,8,16,32,64,128 \mu \mathrm{g} / \mathrm{mL})$ of material at $37{ }^{\circ} \mathrm{C}$ for 18 hours. MIC value was devoted to the least minimum material concentration that observes no bacterial colony.

\section{Time Dynamic Bactericidal Activity}

Time dynamic antibacterial assay was conducted to evaluate the efficiency of PEI-GO nanocomposite over a period of time along with nanocomposite concentration. S. aureus and E. coli $\left(10^{6} \mathrm{CFU} /\right.$ $\mathrm{mL})$ were incubated with a different concentration $(10,20,40 \mu \mathrm{g} /$ $\mathrm{mL}$ ) of PEI-GO nanocomposite. A blank sample as control was also incubated without nanocomposite. Then $100 \mu \mathrm{L}$ sample from above suspension was taken every 30 minutes on time scale zero to 4 hour, diluted in gradient, spread on the LB agar plates and place in incubator for 12 hours at $37^{\circ} \mathrm{C}$. The bacterial colony were counted, and survival \% was calculated in comparison with control samples.

\section{Results and discussion}

PEI-GO nanocomposite synthesis was done by chemical functionalization of GO with PEI by using EDC and NHS as a facilitator. Figure 1 illustrates formation of PEI-GO nanocomposite through the reaction of amine group of PEIs with functional (epoxy and carboxyl) group of GO resulting in the formation of $\mathrm{C}-\mathrm{N}$ bond. The surface morphology of PEI-GO was investigated by TEM (Figures 2a \& 2b). The Figure 2a express the thin layer of GO sheet, whereas Figure $2 b$ clearly indicate the minor wrinkles and folds on GO nanosheet surface. That slight change in the surface morphology can be attributed to the formation of PEI-GO. UVvis absorption spectrum was carried out for GO, PEI and PEI-GO nanocomposite. As shown in Figure 3a, the spectrum of bare GO indicates two representative peaks, the sharp peak is observed at $270 \mathrm{~nm}$ correspond to electronic $\pi-\pi^{*}$ transition of $\mathrm{C}-\mathrm{C}$ aromatic 
bonds, and the shoulder peak is noticed at $300 \mathrm{~nm}$ link to the $\mathrm{n}-\pi^{*}$ transitions of $\mathrm{C}=0$ bonds [45]. For PEI, a sharp absorption peak is observed at $200 \mathrm{~nm}$. On the other hand, the spectrum of PEI-GO is observed same as GO with a fresh absorption peak at $200 \mathrm{~nm}$, witness the conjugation of PEI with GO.

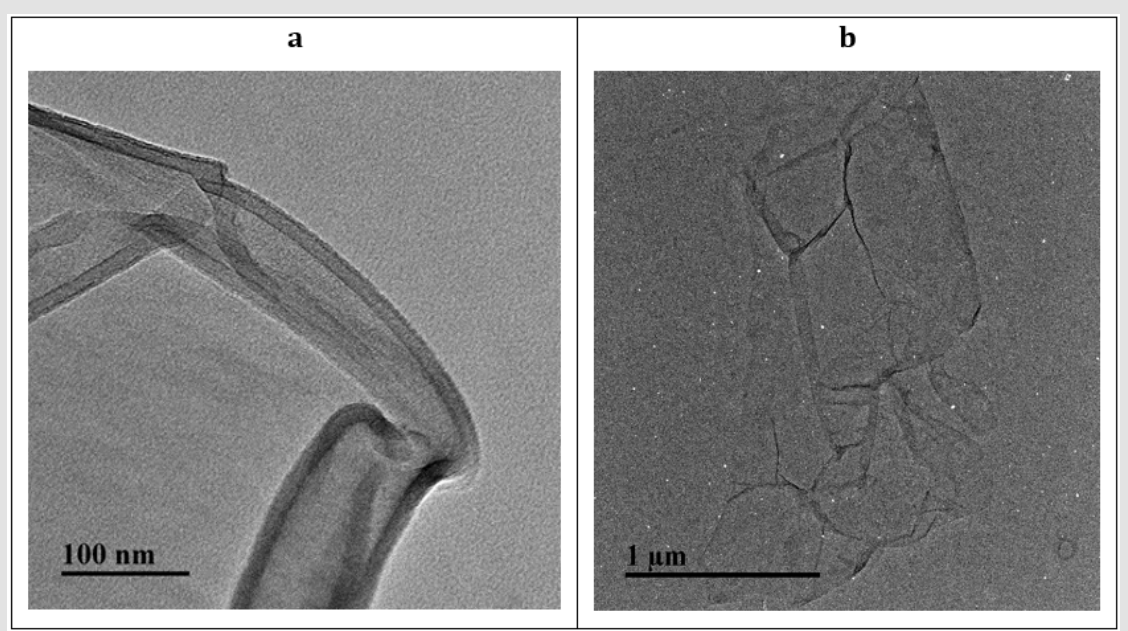

Figure 2: TEM image of (a) GO and (b) PEI-GO

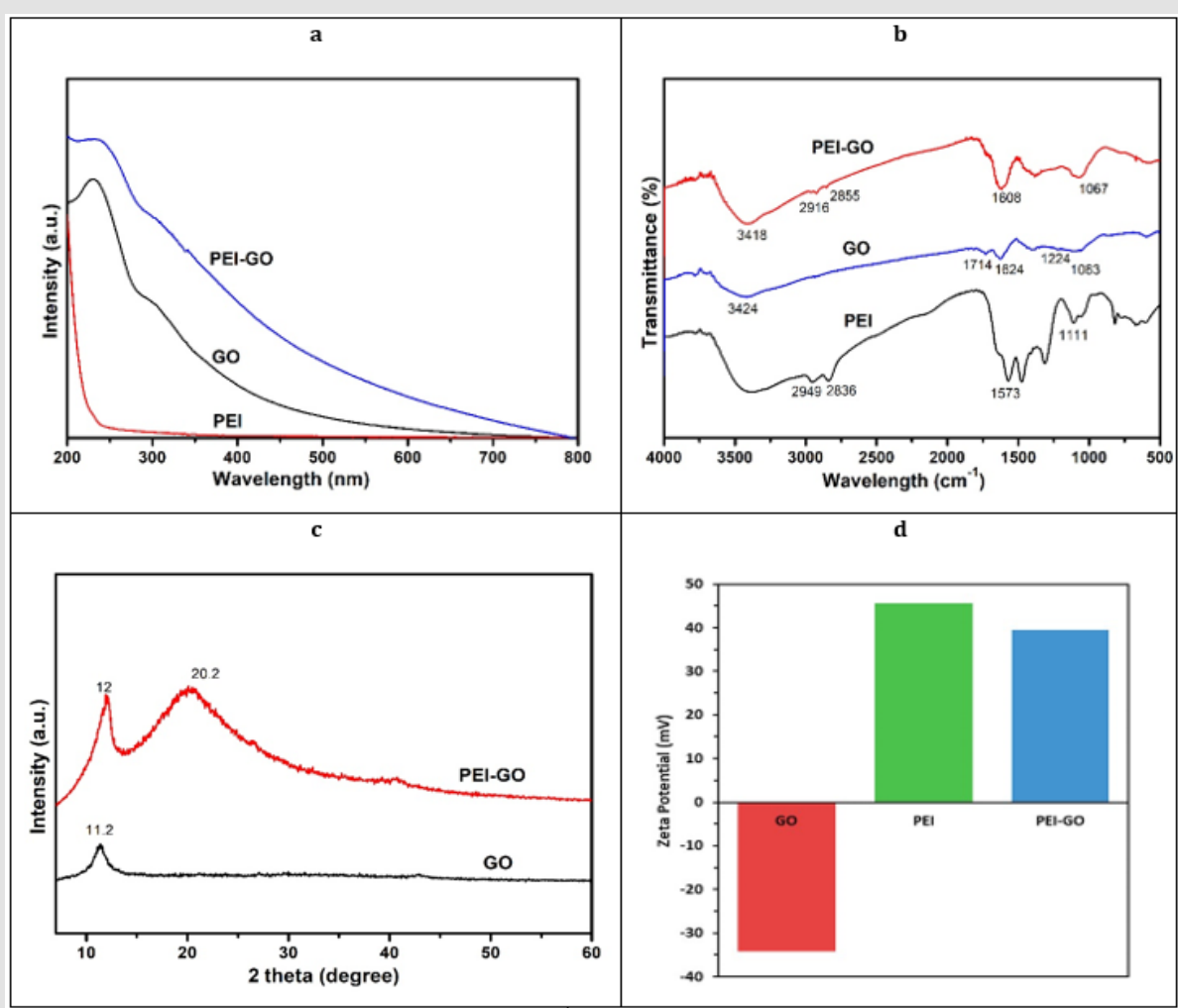

Figure 3: (a) UV-vis. absorption spectra of PEI-GO, GO, and PEI.

(b) FTIR spectra of PEI-GO, GO and PEI.

(c) XRD patterns of PEI-GO and GO.

(d) Zeta-potential of PEI-GO, PEI and GO.

The FTIR spectrophotometer was used to confirm the formation of PEI-GO complex (Figure 3b). In the bare GO spectrum, the main absorption peak at $3424 \mathrm{~cm}^{-1}$ is ascribed to $-\mathrm{OH}$ stretching vibration. The peak at $1714 \mathrm{~cm}^{-1}$ shows the Stretching vibration of carboxyl functional group of GO. Whereas the band $1624 \mathrm{~cm}^{-1}$ is considered as $\mathrm{C}=\mathrm{C}$ aromatic Stretching, that at $1224 \mathrm{~cm}^{-1}$ and $1063 \mathrm{~cm}^{-1}$ are assigned to epoxy C-O stretching vibration [46]. The Infrared spectrum of PEI indicates absorption peak at 1573 $\mathrm{cm}^{-1}$, and $1111 \mathrm{~cm}^{-1}$ are linked to the bend vibration of $\mathrm{N}-\mathrm{H}$ bond of primary and secondary amine groups, respectively [38]. After 
PEI and GO reaction, downshift in a peak at $3418 \mathrm{~cm}^{-1}$ is observed assign to hydroxyl stretching, and two other peaks are gained at 2916 and $2855 \mathrm{~cm}^{-1}$, ascribed to the symmetric and asymmetric stretching mode of PEI methylene groups [47]. The peak at 1714 $\mathrm{cm}^{-1}$ is hardly noticeable, and a new strong peak is detected at 1608 $\mathrm{cm}^{-1}$ indicate the stretching mode of amide bond because of the reaction of polyethylenimine $-\mathrm{NH}_{2}$ groups with graphene oxide $\mathrm{COOH}$ groups. Furthermore, disappearance of peak at $1224 \mathrm{~cm}^{-1}$, and the prominent peak at $1067 \mathrm{~cm}^{-1}$ also indicate the formation of $\mathrm{C}-\mathrm{N}$ bond via epoxy groups of GO and amine groups of PEIs.

XRD measurements were performed to determine the changes in the crystalline structure of GO before, and after functionalization with PEI. As presented in Figure 3c, the XRD pattern of bare GO expresses one characteristic peak at $2 \theta=11.2^{\circ}$ corresponding to the (001) crystalline plane having an interlayer-spacing $0.793 \mathrm{~nm}$. This interlayer-spacing is because of the oxygen-bearing functional groups of GO present in the layers [12]. After PEI conjugation with GO, two peaks are observed, the broad peak at $2 \theta=20.2^{\circ}$ might be assigned to the non-crystalline diffraction of PEI, and the peak at $2 \theta=12^{\circ}$ relate to the (001) plane with an interlayer spacing 0.741 $\mathrm{nm}$ compared to GO. This right-shift and reduction in interlayer spacing are probably due to the presence of PEI in the PEI-GO nanocomposite. The zeta potential (mV) measurement of GO, PEI, and PEI-GO is shown in Figure 3d. GO exhibit negative zeta potential of $-34.2 \mathrm{mV}$ owing to its functional groups (hydroxyl, epoxy and carboxyl) on its basal and edges plain, whereas PEI is highly cationic polymer having zeta potential of $45.6 \mathrm{mV}$. After functionalization of GO, our nanocomposite indicate positive zeta potential of $39.4 \mathrm{mV}$, confirms the successful functionalization of GO with PEI.

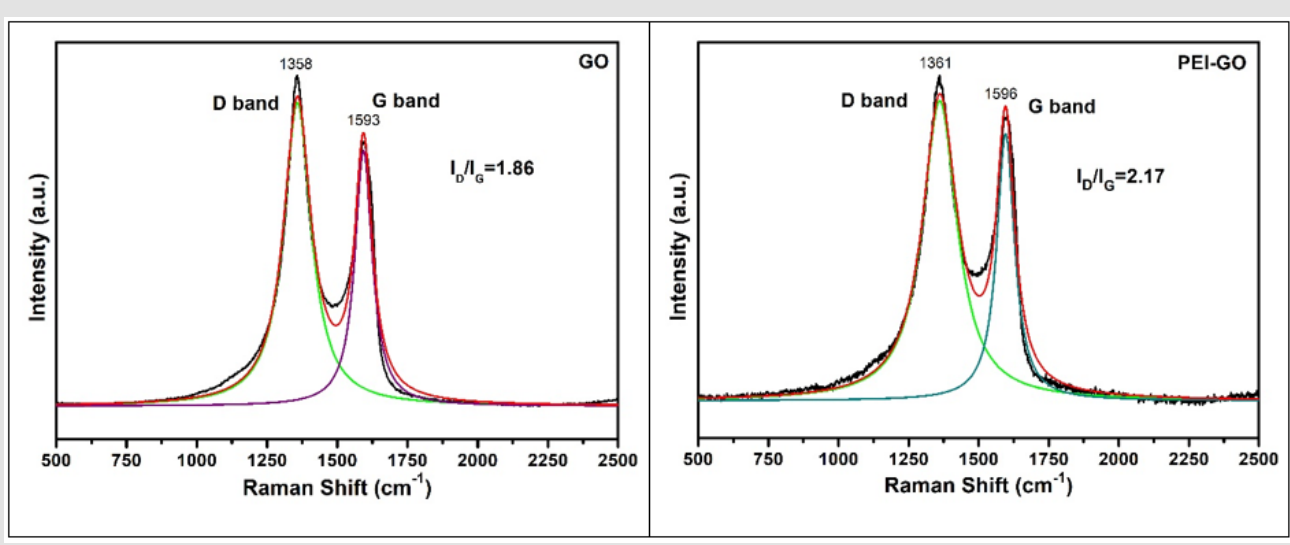

Figure 4: Raman spectroscopy spectra of bare graphene oxide and PEI-GO nanocomposite.

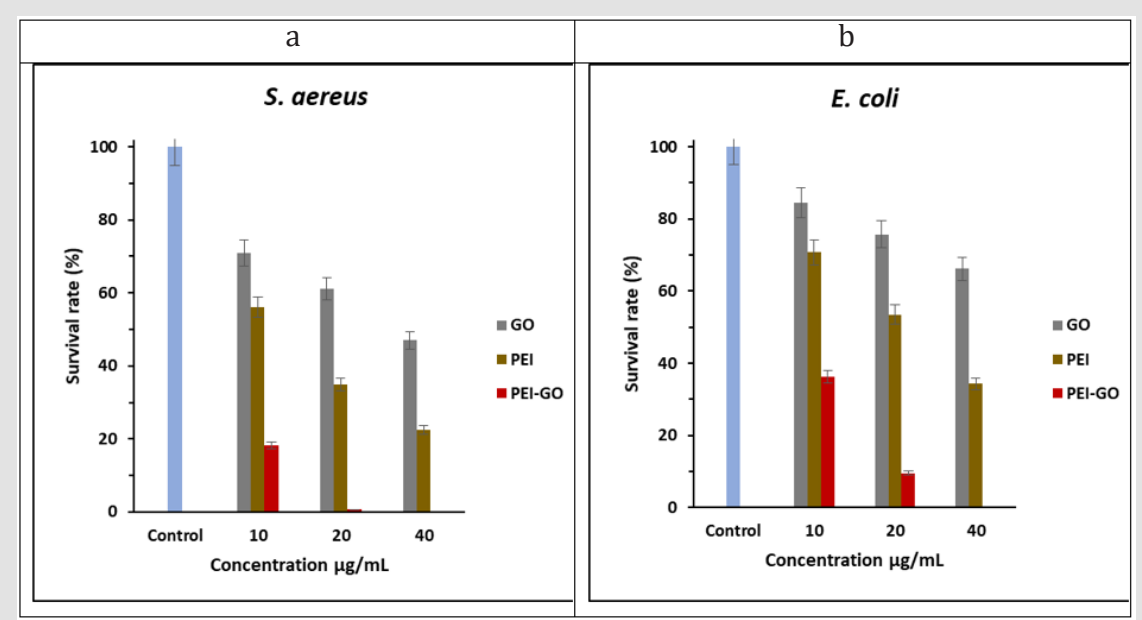

Figure 5: Survival rate (in \%) of S. aureus and E. coli after 5 hours of treatment with 10, 20, and $40 \mu \mathrm{g} / \mathrm{mL}$, concentration of GO, PEI, PEI-GO. Error bars indicate a standard error in three experiments.

Figure 4 presents the Raman spectra for bare graphene oxide and PEI-GO nanocomposite. Raman spectra of both bare GO as well as PEI-GO shows two main noticeable peaks denoted as D band and $\mathrm{G}$ band. The D band demonstrate the breathing mode of $\kappa$-point phonons of $A_{1 g}$ symmetry and structural imperfection in graphene sheet; however, the $\mathrm{G}$ band arise from the first order scattering of $\mathrm{E}_{2 \mathrm{~g}}$ phonons of $\mathrm{sp}^{2}$ carbon atom $[48,49]$. The Raman spectra of GO is found at 1358 and $1593 \mathrm{~cm}^{-1}$, for D band and G band, respectively, whereas for PEI functionalized graphene oxide the D and G band obtained are located at 1361 and $1596 \mathrm{~cm}^{-1}$, respectively. Additionally, the degree of disorder in GO structure can be estimated by calculating the $\mathrm{I}_{\mathrm{D}} / \mathrm{I}_{\mathrm{G}}$ ratio. From our results, 
the Raman shift in D band and G band are clearly observed after functionalisation of GO with PEI. Moreover, the increase in $I_{D} / I_{G}$ ratio in PEI-GO as compared to GO from 1.86 to 2.17 clarifies the increase in structural disorders in PEI-GO.

Table 1: MIC values of different material against $S$. aureus and E. coli. "_" represent the MIC value were undetectable even at concentration $128 \mu \mathrm{g} / \mathrm{mL}$.

\begin{tabular}{|c|c|c|}
\hline \multirow{2}{*}{ Material } & \multicolumn{2}{|c|}{ MIC $\mu \mathrm{g} / \mathrm{mL}$} \\
\cline { 2 - 3 } & S. aureus & E. coli \\
\hline GO & - & - \\
\hline PEI & 64 & 128 \\
\hline PEI-GO & 8 & 16 \\
\hline
\end{tabular}

\section{Antibacterial Activity}

The antibacterial activity of GO, PEI, PEI-GO were tested against $S$. aureus and E. coli by calculating the survival cells after 5 hours incubation with require concentration of well-dispersed each nanocomposite followed by growth on agar plate. For comparison, control samples were incubated in $0.85 \%$ saline solution without any nanocomposite. Figures $5 \mathrm{a} \& 5 \mathrm{~b}$ describes the survival \% of bacterial colonies after treatment with nanocomposite. As compared to the control sample, all three materials indicate concentration dependant reduction in the bacterial viabilities. It can be seen in Figure 5, at concentration of $40 \mu \mathrm{g} / \mathrm{mL}$ of PEI-GO, $100 \%$ reduction of $S$. aureus and E. coli are achieved, whereas in case of GO and PEI, the same above concentration of $40 \mu \mathrm{g} / \mathrm{mL}$ could only reduce the $S$. aureus viabilities to $46.9 \%, 22.5 \%$ and $E$. coli viabilities to $66.1 \%, 34.2 \%$. In Figure 5a, shows $S$. aureus survival rate, almost all bacteria (99.4\%) are killed with concentration of $20 \mu \mathrm{g} / \mathrm{mL}$ PEI-GO while with $10 \mu \mathrm{g} / \mathrm{mL}$ PEI-GO bacterial count is reduced to $18.3 \%$. Moreover, GO and PEI at concentration of $10 \mu \mathrm{g} / \mathrm{mL}$ have reduced the bacterial colonies to $71 \%$ and $56.1 \%$, while $20 \mu \mathrm{g} / \mathrm{mL}$ of GO and PEI reduced the colonies to $61.1 \%$ and $34.9 \%$

Beside complete reduction of E. coli at $40 \mu \mathrm{g} / \mathrm{mL}$ PEI-GO (Figure 5b), $36.2 \%$ and $9.5 \%$ survival rate of bacteria is observed at 10 and $20 \mu \mathrm{g} / \mathrm{mL}$ of PEI-GO. The survival rate of $E$. coli is $84.4 \%, 75.7 \%$ and $66.1 \%$ with 10,20 and $40 \mu \mathrm{g} / \mathrm{mL}$ of bare GO concentration indicating poor bactericidal activity, however, the survival \% of $E$. coli population is $70.7 \%, 53.4 \%$ and $34.2 \%$ with PEI at concentration of 10, 20 and $40 \mu \mathrm{g} / \mathrm{mL}$. Our prepared nanocomposite PEI-GO exhibits stronger antibacterial activity among GO, PEI and PEI-GO against both model strains. In our study the susceptibility of $S$. aureus to PEI-GO found to be stronger comparing E. coli. In comparison to $E$. coli, S. aureus shows nearly complete inhibition at $20 \mu \mathrm{g} / \mathrm{mL}$, which can be seen in Figure 5a. The difference in bacterial reduction could be attributed to more resistance of E. coli as compared to $S$. aureus. Although S. aureus (Gram-positive bacteria) contain a thick layer of peptidoglycan in its membrane (thickness range $20-80 \mathrm{~nm}$ ), but it lacks an outer membrane. In contrast, E. coli (Gram-negative bacteria) encompasses a thin layer of peptidoglycan (thickness range 7 - $8 \mathrm{~nm}$ ), but it keeps another additional layer known as the outer membrane in its structure, this outer membrane of E. coli express resistance to the direct contact of bacteria with nanocomposite [27,50,51].

Moreover, PEI exhibit significantly higher bacterial inhibition rate towards Gram-positive bacteria [35], this could be attributed to greater cationic charge transfer onto the negative charge membrane, which increases the cell permeability [52] as well as to the absence of an outer membrane. After PEI conjugation to GO, the bactericidal activity of PEI-GO nanocomposite increased significantly against both the model strains. Minimum inhibitory concentration is a crucial parameter to determine the antibacterial ability of the given material towards specific bacteria. MIC test was performed to compare the MIC values of PEI-GO, GO, and PEI for $S$. aureus and E. coli shown in Table 1. As expected, PEI-GO shows the lowest MIC values among the three materials. The MIC of GO was undetectable even at concentration $128 \mu \mathrm{g} / \mathrm{mL}$ for both $S$. aureus and $E$. coli showing very week antibacterial activity and highest MIC value. However, MIC of PEI is obtained to be $64 \mu \mathrm{g} / \mathrm{mL}$ for $S$. aureus and $128 \mu \mathrm{g} / \mathrm{mL}$ for E. coli. In addition, with PEI-GO the growth of $S$. aureus was invisible at concentration $8 \mu \mathrm{g} / \mathrm{mL}$ or above, and growth of $E$. coli was inhibited entirely at concentration $16 \mu \mathrm{g} / \mathrm{mL}$ or above making their MIC values $8 \mu \mathrm{g} / \mathrm{mL}$ and $16 \mu \mathrm{g} / \mathrm{mL}$ respectively.

Lowest MIC value of PEI-GO is due to the synergistic effect of both constituents of nanocomposite. Antibacterial analysis reveals that PEI show superior inhibition activity towards $S$. aureus than $E$. coli [35]. Time dynamic bactericidal activity of PEI-GO was assessed against $S$. aureus and E. coli. The bacteria were exposed to different concentration of PEI-GO nanocomposite, and their survival rate was calculated in correlation with blank control over a half-hour (h) time interval from 0 to $4 \mathrm{~h}$. we kept the concentration of PEIGO nanocomposite same as we used in the antibacterial activity assay to understand the change in survival rate with time and concentration. Figure 6 shows the time dynamic curves of $S$. aureus and E. coli treated with PEI-GO. Bacterial survival rate inversely correlates with the concentration and exposure time of PEI-GO, with high concentration of nanocomposite the bactericidal time was shortened, and survival rate of bacteria decreased. As in Figure $6 \mathrm{a}$, the survival rate of $S$. aureus at concentration $40 \mu \mathrm{g} / \mathrm{mL}$ after $2.5 \mathrm{~h}$ treatment was $1.9 \%$, later half more hour (after $3 \mathrm{~h}$ ) that was found 0 , which means that $S$. aureus was inhibited entirely inbetween 2.5 to $3 \mathrm{~h}$ duration. In case of E. coli (Figure $6 \mathrm{~b}$ ) after 2.5 h with $40 \mu \mathrm{g} / \mathrm{mL}$ nanocomposite, the survival rate was $7.3 \%$, and complete reduction was achieved near $3.5 \mathrm{~h}$. 


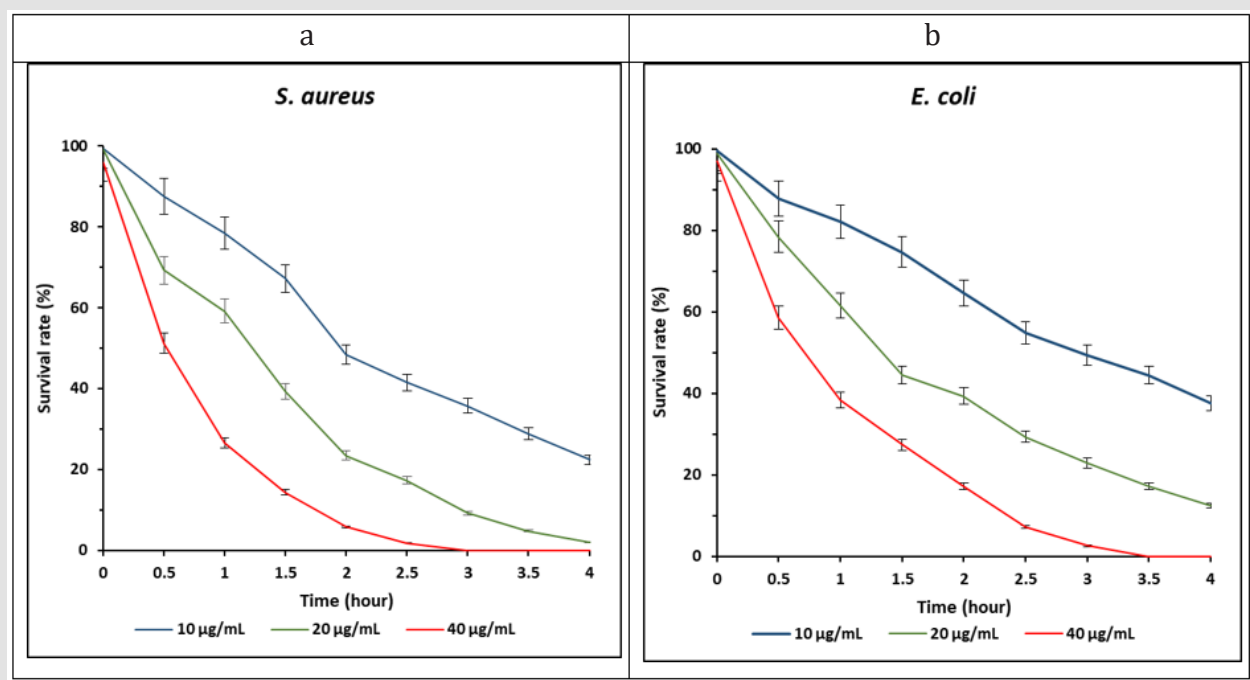

Figure 6: Time dynamic survival \% of (a) S. aureus (b) E. coli over a half-hour difference of time at different concentration (10, $2040 \mu \mathrm{g} / \mathrm{mL}$ ) of PEI-GO. Error bars indicate standard error from three experiment.

Furthermore, S. aureus survival rate after $2.5 \mathrm{~h}$, with concentration 10 and $20 \mu \mathrm{g} / \mathrm{mL}$ were $41.5 \%$ and $17.3 \%$ respectively, while those of $E$. coli after $2.5 \mathrm{~h}$ exposure to 10 and $20 \mu \mathrm{g} / \mathrm{mL}$, the survival rate were $54.9 \%$ and $29.3 \%$ respectively. Comparison of $S$. aureus and $E$. coli revealed that the decrease in survival rate was observed quicker in $S$. aureus than E. coli with PEI-GO nanocomposite. In addition, with $40 \mu \mathrm{g} / \mathrm{mL}$ PEI-GO about $70 \%$ and $60 \%$ of the reduction was achieved within first-hour exposure of $S$. aureus and E. coli, then moved gradually to the complete reduction about/after 3 and $3.5 \mathrm{~h}$ respectively. With 10 and $20 \mu \mathrm{g} / \mathrm{mL}$ concentration, the reduction in survival rate was bit quicker in the beginning than in later stage, after $4 \mathrm{~h}$ the survival rate of $S$. aureus and E. coli was $1.9 \%$ and $12.4 \%$ with $20 \mu \mathrm{g} / \mathrm{mL}$ nanocomposite. The difference in reduction of survival rate between $S$. aureus and $E$. coli is because of bacterial structural difference, which has been discussed above and enhanced destructive capability of PEI against Gram-positive bacteria [53]. From the graph, it is revealed that with increasing concentration, rapid reduction in survival rate can be obtained. However, less concentration requires more time to attain high bactericidal activity. The difference in reduction rate in the beginning and later stage could be attributed to the reduction in live bacterial cells and covering of nanocomposite with bacterial residues.

\section{Possible Bactericidal Phenomena}

The bactericidal property is attributed to the damage caused by the PEI-GO by direct contact to the bacterial membrane. The positive charge PEI has ability to bind negatively charged cell surface and increase the cell permeability causing destruction of bacterial membrane integrity. In addition, PEI can bind to phospholipid and various cellular material disturbing the cell functionality [53]. The sharp edges of GO can pierce the bacterial membrane and produce membrane stress in the cell that degrades the bacterial morphology and outflow of protoplasm, cause the destruction of bacteria leading to osmotic difference and ultimately bacterial death $[27,28,54]$. The even distribution of PEI on the GO surface increase the binding affinity to the bacterial cell membrane. The amine group of PEI attach to the bacterial membrane inducing structural damage whereas the sharp edges of GO penetrate and disrupt the membrane, resulting in the release of protoplasmic fluid and consequently cell lysis. The enhanced bactericidal activity of PEI-GO is because of the synergistic effect of both materials.

\section{Conclusion}

In the present study, we have synthesized Polyethylenimine grafted graphene oxide nanocomposite (PEI-GO) via $\mathrm{C}-\mathrm{N}$ bond by utilizing EDC and NHS as a facilitator agent, which was confirmed by characterization. The antibacterial property of prepared material was investigated against Gram-positive and Gram-negative bacteria. MIC value of $S$. aureus was found to be lower $(8 \mu \mathrm{g} / \mathrm{mL})$ than that of E. coli $(16 \mu \mathrm{g} / \mathrm{mL})$, which might be because of $E$. coli resistance to the direct contact interaction with material owing to the presence of an outer membrane and the high susceptibility of $S$. aureus to PEI, besides the lack of outer membrane in its structure can be a possible reason. Moreover, results from time dynamic bactericidal curves show that the survival rate is inversely proportional to the concentration of material as well as to contact time. The antibacterial test shows the significant bactericidal property of PEI-GO nanocomposite at low dosage compared to PEI and GO alone, which was attributed to the better charge transfer of PEI onto the negative charge membrane and sharp edges of GO causing the ultimate cell destruction. Our prepared nanocomposite can be a promising antibacterial agent to fight against pathogens from attaining resistance.

\section{Competing Interest}

The authors declare no competing interest. 


\section{References}

1. Liu YY, Wang Y, Walsh TR, Yi LW, Zhang R, et al. (2015) Emergence of plasmid-mediated colistin resistance mechanism MCR-1 in animals and human beings in China: A microbiological and molecular biological study. The Lancet Infectious Diseases 16(2): 161-168.

2. Webb GF, D'Agata EMC, Magal P, Ruan S (2005) A model of antibioticresistant bacterial epidemics in hospitals. Proceedings of the National Academy of Sciences of the United States of America 102(37): 13343 13348.

3. Van Boeckel TP, Gandra S, Ashok A, Caudron Q, Grenfell BT, et al. (2014) Global antibiotic consumption 2000 to 2010: an analysis of national pharmaceutical sales data. The Lancet infectious diseases 14(8): 742750.

4. Slavin YN, Asnis J, Häfeli UO, Bach H (2017) Metal nanoparticles: understanding the mechanisms behind antibacterial activity. Journal of Nanobiotechnology 15(1): 65.

5. Liu C, Shen J, Yeung KWK, Tjong SC (2017) Development and Antibacterial Performance of Novel Polylactic Acid-Graphene OxideSilver Nanoparticle Hybrid Nanocomposite Mats Prepared By Electrospinning. ACS Biomaterials Science \& Engineering 3(3): 471-486.

6. Aruguete DM, Kim B, Hochella MF, Ma Y, Cheng Y, et al. (2013) Antimicrobial nanotechnology: its potential for the effective management of microbial drug resistance and implications for research needs in microbial nanotoxicology. Environmental Science: Processes \& Impacts 15(1): 93-102.

7. Novoselov KS, Fal'ko VI, Colombo L, Gellert PR, Schwab MG, et al. (2012) A roadmap for graphene. Nature 490(7419): 192-200.

8. Gao N, Y Chen, J Jiang (2013) Ag@Fe203-GO Nanocomposites Prepared by a Phase Transfer Method with Long-Term Antibacterial Property. ACS Applied Materials \& Interfaces 5(21): 11307-11314.

9. Berger C, Song Z, Li X, Wu X, Brown N, et al. (2006) Electronic Confinement and Coherence in Patterned Epitaxial Graphene. Science 312(5777): 1191-1196.

10. Sanchez VC, Jachak V, Hurt RH, Kane AB (2012) Biological Interactions of Graphene-Family Nanomaterials: An Interdisciplinary Review. Chemical Research in Toxicology 25(1): 15-34.

11. Zhang Q, Wu Z, Li N, Pu Y, Wang B, et al. (2017) Advanced review of graphene-based nanomaterials in drug delivery systems: Synthesis, modification, toxicity and application. Materials Science and Engineering: C 77: 1363-1375.

12. Díez Pascual AM, AL Díez Vicente (2016) Poly(propylene fumarate)/ Polyethylene Glycol-Modified Graphene Oxide Nanocomposites for Tissue Engineering. ACS Applied Materials \& Interfaces 8(28): 1790217914.

13. Perreault F, Fonseca de Faria A, Elimelech M (2015) Environmental applications of graphene-based nanomaterials. Chemical Society Reviews 44(16): 5861-5896

14. Feng L, Z Liu (2011) Graphene in biomedicine: Opportunities and challenges. Nanomedicine (London, England) 6(2): 317-324.

15. Abdullah Al N, Lee JE, In I, Lee H, Dae Lee K, et al. (2013) Target Delivery and Cell Imaging Using Hyaluronic Acid-Functionalized Graphene Quantum Dots. Molecular Pharmaceutics 10(10): 3736-3744.

16. Yang K, Hu L, Ma X, Ye S, Cheng L, et al. (2012) Multimodal Imaging Guided Photothermal Therapy using Functionalized Graphene Nanosheets Anchored with Magnetic Nanoparticles. Advanced Materials 24(14): 1868-1872.

17. Hu W, Peng C, Luo W, Lv M, Li X, et al. (2010) Graphene-Based Antibacterial Paper. ACS Nano 4(7): 4317-4323.
18. Lee C, Wei X, Kysar JW, Hone J (2008) Measurement of the Elastic Properties and Intrinsic Strength of Monolayer Graphene. Science, 2008. 321(5887): 385-388

19. Geim AK, KS Novoselov (2007) The rise of graphene. Nature Materials 6(3): 183-191.

20. Dreyer DR, Park S, Bielawski CW, Ruoff RS (2010) The chemistry of graphene oxide. Chemical Society Reviews 39(1): 228-240.

21. He H, Klinowski J, Forster M, Lerf A (1998) A new structural model for graphite oxide. Chemical Physics Letters 287(1): 53-56.

22. Dreyer DR, Todd AD, Bielawski CW (2014) Harnessing the chemistry of graphene oxide. Chemical Society Reviews 43(15): 5288-5301.

23. Liu Z, Robinson JT, Sun X, Dai H (2008) PEGylated nanographene oxide for delivery of water-insoluble cancer drugs. Journal of the American Chemical Society 130(33): 10876-10877

24. Zhang H, Yan T,Xu S, Feng S, Huang D, etal.(2017) Graphene oxide-chitosan nanocomposites for intracellular delivery of immunostimulatory CpG oligodeoxynucleotides. Materials Science and Engineering: C 73: 144151.

25. Kim H, Namgung R, Singha K, Kwon Oh I, Kim WJ (2011) Graphene Oxide- Polyethylenimine Nanoconstruct as a Gene Delivery Vector and Bioimaging Tool. Bioconjugate Chemistry 22(12): 2558-2567.

26. Nanda SS, SSA An, DK Yi (2015) Oxidative stress and antibacterial properties of a graphene oxide-cystamine nanohybrid. International journal of nanomedicine 10: 549-556.

27. Akhavan O, E Ghaderi (2010) Toxicity of Graphene and Graphene Oxide Nanowalls Against Bacteria. ACS Nano 4(10): 5731-5736.

28. Chen J, Peng H, Wang X, Shao F, Yuan Z, et al. (2014) Graphene oxide exhibits broad-spectrum antimicrobial activity against bacterial phytopathogens and fungal conidia by intertwining and membrane perturbation. Nanoscale 6(3): 1879-1889.

29. Gurunathan S, Han JW, Dayem AA, Eppakayala V, Kim JH (2012) Oxidative stress-mediated antibacterial activity of graphene oxide and reduced graphene oxide in Pseudomonas aeruginosa. International journal of nanomedicine 7: 5901-5914.

30. Liu S, Zeng TH, Hofmann M, Burcombe E, Wei J, et al. (2011) Antibacterial Activity of Graphite, Graphite Oxide, Graphene Oxide, and Reduced Graphene Oxide: Membrane and Oxidative Stress. ACS Nano 5(9): 69716980.

31. Barbolina I, Woods CR, Lozano N, Kostarelos K, Novoselov KS, et al (2016) Purity of graphene oxide determines its antibacterial activity. 2D Materials 3(2): 025025.

32. Xie X, Mao C, Liu X, Zhang Y, Cui Z, et al. (2017) Synergistic BacteriaKilling through Photodynamic and Physical Actions of Graphene Oxide/ Ag/Collagen Coating. ACS Applied Materials \& Interfaces 9(31): $26417-$ 26428.

33. Marta B, Potara M, Iliut M, Jakab E, Radu T, et al. (2015) Designing chitosan- silver nanoparticles- graphene oxide nanohybrids with enhanced antibacterial activity against Staphylococcus aureus. Colloids and Surfaces A: Physicochemical and Engineering Aspects 487: 113-120.

34. Paola V, Giuliano A, Ortaggi G, Masotti A (2008) Polyethylenimine In Medicinal Chemistry. Current Medicinal Chemistry 15(27): 2826-2839.

35. Yudovin Farber I, Golenser J, Beyth N, Weiss EI, Domb AJ (2010) Quaternary ammonium polyethyleneimine: antibacterial activity. Journal of nanomaterials pp. 826343.

36. Zakeri A, Kouhbanani MAJ, Beheshtkhoo N, Beigi V, Mousavi SM, et al. (2018) Polyethylenimine-based nanocarriers in co-delivery of drug and gene: a developing horizon. Nano Reviews \& Experiments 9(1): 1488497.

37. Xu D, Wang Q, Yang T, Cao, Lin Q et al. (2016) Polyethyleneimine Capped 
Silver Nanoclusters as Efficient Antibacterial Agents. International journal of environmental research and public health 13(3): 334 .

38. Gao B, Zhang X, Zhu Y (2007) Studies on the preparation and antibacterial properties of quaternized polyethyleneimine. Journal of Biomaterials Science Polymer Edition 18(5): 531-544.

39. Azevedo MM, Ramalho P, Silva AP, Teixeira Santos R, Pina Vaz C, et al. (2014) Polyethyleneimine (PEI) and PEI-Based nanoparticles: innovative bacterial and yeast biofilm inhibitors. Journal of medical microbiology 63(Pt 9): 1167-1173.

40. Mallakpour S, Abdolmaleki A, Borandeh S (2014) Covalently functionalized graphene sheets with biocompatible natural amino acids. Applied Surface Science 307: 533-542

41. Park S, Dikin DA, Nguyen ST, Ruoff RS (2009) Graphene Oxide Sheets Chemically Cross-Linked by Polyallylamine. Journal of Physical Chemistry C - J PHYS CHEM C 113(36): 15801-15804.

42. Zhang L, Lu Z, Zhao Q Huang J, Shen H, et al. (2011) Enhanced Chemotherapy Efficacy by Sequential Delivery of siRNA and Anticancer Drugs Using PEI-Grafted Graphene Oxide. Small 7(4): 460-464.

43. Cao W, Yue L, Wang Z (2019) High antibacterial activity of chitosan molybdenum disulfide nanocomposite. Carbohydrate Polymers 215: 226-234.

44. Andrews JM (2001) Determination of minimum inhibitory concentrations. Journal of Antimicrobial Chemotherapy 48(suppl_1): p. $5-16$.

45. De Faria AF, Martinez DST, Meira SMM, De Moraes ACM, Brandelli A, et al.

ISSN: 2574-1241

DOI: 10.26717/BJSTR.2020.27.004477

Lin Yue and Zhouping Wang. Biomed J Sci \& Tech Res

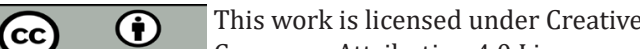
Commons Attribution 4.0 License

Submission Link: https://biomedres.us/submit-manuscript.php
(2014) Anti-adhesion and antibacterial activity of silver nanoparticles supported on graphene oxide sheets. Colloids and Surfaces B: Biointerfaces 113: 115-124.

46. Rattana, Chaiyakun S, Witit anun N, Nuntawong N, Chindaudom P, et al. (2012) Preparation and characterization of graphene oxide nanosheets. Procedia Engineering 32: 759-764.

47. Qin SY, Feng J, Rong L, Jia HZ, Chen S, et al. (2014) Theranostic GO-Based Nanohybrid for Tumor Induced Imaging and Potential Combinational Tumor Therapy. Small 10(3): 599-608.

48. Zhang J, Yang H, Shen G, Cheng P, Zhang J, et al. (2010) Reduction of graphene oxide vial-ascorbic acid. Chemical Communications 46(7): 1112-1114.

49. Strankowski M, Włodarczyk D, Piszczyk L, Strankowska J (2016) Polyurethane Nanocomposites Containing Reduced Graphene Oxide, FTIR, Raman, and XRD Studies. Journal of Spectroscopy 2016: 7520741.

50. Eaton P, Fernandes JC, Pereira E, Pintado ME, Malcata FX (2008) Atomic force microscopy study of the antibacterial effects of chitosans on Escherichia coli and Staphylococcus aureus. Ultramicroscopy 108(10): 1128-1134.

51. Ghai I, Ghai S (2018) Understanding antibiotic resistance via outer membrane permeability. Infection and drug resistance 11: 523-530.

52. Beyth N, Houri Haddad Y, Baraness Hadar L, Yudovin Farber I, Domb AJ, et al. (2008) Surface antimicrobial activity and biocompatibility of incorporated polyethylenimine nanoparticles. Biomaterials 29(31): 4157-4163.

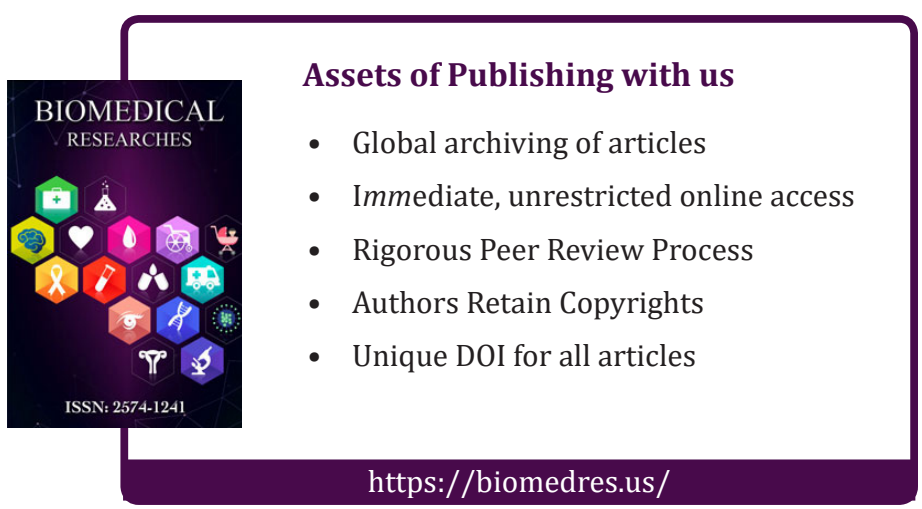

